\title{
Sustainable and energy-efficient rehabilitation of the former hospital of San Salvatore in L'Aquila
}

\author{
P. De Berardinis, L. Capannolo \& C. Marchionni \\ Civil, Building/Architecture and Environmental Engineering (DICEAA), \\ University of L'Aquila, Italy
}

\begin{abstract}
The topic of sustainable rehabilitation of historic buildings is currently really important in the town of L'Aquila. After the earthquake of 2009, the project aims in the field of energy efficiency and the use of innovative technologies and materials are integrated with the necessary reconstruction interventions and with the refurbishment of the heritage buildings.

The transition from a "traditional" to an eco-efficient building takes place more easily and with greater emphasis in the planning of new buildings, through the introduction of a high potential in terms of experimentation and applied research on building systems and components. The refurbishment of existing buildings raises several questions and presents considerable difficulties, especially when the intervention involves a building bearer of intrinsic meaning and historical, constructive and cultural values.

The former hospital of San Salvatore is a building complex located in the historic center of L'Aquila. It has been left devoid of any function since the end of the twentieth century, so it has undergone a gradual degradation, aggravated by the earthquake damage. The refurbishment of the building has affected the functional-spatial, figurative, energetic and structural aspects. The intervention mainly consists of the reuse of the building in order to create a university campus, in the extension of it through new elements that respect the original system, in the replacement of building elements affected by technological problems and in the integration of new elements in the pre-existing building, cooperating with it in terms of structural and energetic performance.

The main purpose of this paper is to define a methodological approach for the sustainable rehabilitation of the historic buildings, by retracing the steps of
\end{abstract}


assessment and analysis addressed in the refunctionalization and energy-efficient rehabilitation of the former hospital of San Salvatore in L'Aquila.

Keywords: reuse, energy-efficient rehabilitation, built heritage, sustainability, innovative technologies.

\section{Introduction}

The refurbishment of the historical buildings, apart from considering all aspects related to the recognition of the values to be protected, cannot be separated from the identification of appropriate strategies for the energy-environment management of existing buildings, able to improve their usability [1].

In fact, it is true that "recovery of the existing buildings means getting them back to be an integral and living part of the tissues of cities and countries. It means bringing them to life with new functional vocations, sometimes new compared to the past, sometimes similar to those that have always been offered... Essentially, we need to have the courage to recognize, support and defend the many historical, architectural, technological values, which are written in the walls, in the volumes, in the tables, in the forms of the existing buildings. The refurbishment, therefore, must be an act of courage and will" [2].

The aim of preserving and enhancing the identity of places through the knowledge of their determinant characters, in fact, is combined with the simultaneous analysis of the urban transformation projects. They generated by changing social needs, and the necessity to develop the processes from the point of view of the efficacy, cheapness and sustainability.

In addition, the sustainable building cannot be an exclusive prerogative of the interventions of new buildings: topics like the reduction of energy consumption and the improvement of environmental quality should be extended beyond the urban forms and structures of greater dimensional impact, reaching systematically even the cores that characterize the historic town.

An example is the former hospital complex of San Salvatore, situated in the town center, immediately outside the town walls. It is the result of continuous transformations, sometimes radical, that have occurred over time, in order to adapt the original plant to the functional and hygienic needs required [3].

This complex, in which the structures of the former monastery of Santa Agnese have been incorporated, has undergone, during the twentieth century, numerous extensions. They have been configured in buildings with their own architectural connotation or that constitute real superfetations, these latter designed to supply the functional needs of the whole hospital. The architectural, distributive and structural features of the building, reflecting the different periods of construction (one in the eighteenth century, one that occurred in 1930 and one in the 1950s), have led to an irregular planimetric shape which extends vertically on four floors, one of which is underground [4-7], fig. 1.

The building, no longer strategic for the health activities of the company ASL n. 4, after the transfer of all divisions in the new complex built in the village of Lenze di Coppito (AQ) at the end of the twentieth century, was left without any 


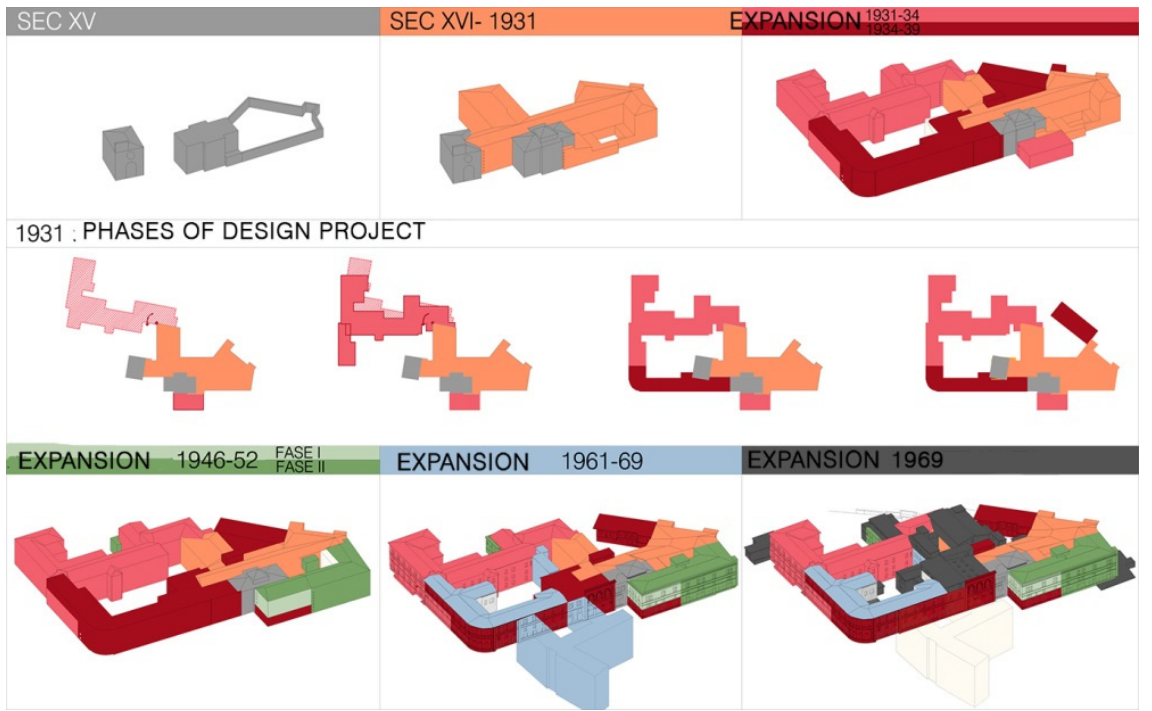

Figure 1: The historical phases.

function. Nothing could ensure the preservation in good condition over time, causing a gradual degradation, aggravated by the damage of the earthquake that struck the city in 2009, fig. 2.

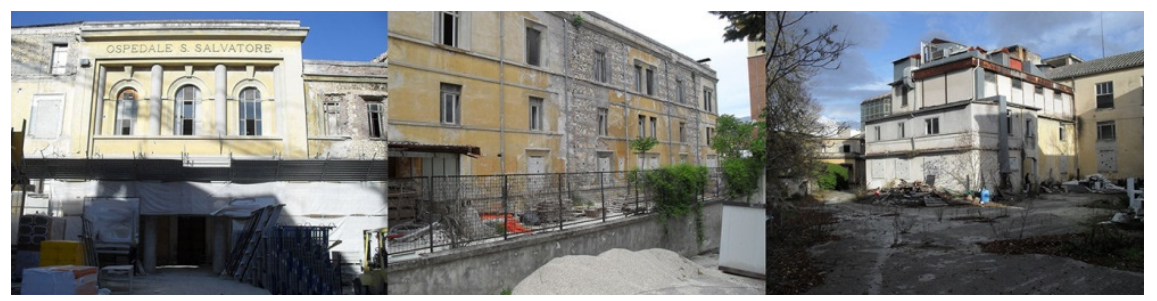

Figure 2: Current situation.

The environmentally friendly refurbishment of the building, currently owned by the University of L'Aquila, has affected the functional-spatial, figurative, energetic and structural aspects. It is part of a broader strategic plan for the redevelopment of the entire urban area of relevance, and it has resulted in the creation of an integrated campus with cultural, recreational, residential and sport activities, to support the training and research functions.

\section{The design proposal of refunctionalization (1)}

The earthquake of April 6, 2009 has caused significant effects on the whole university system of L'Aquila. It caused the almost total unavailability of the 
entire building heritage of the town and its area, with the resetting of the offer of residences for students, and significant impact on the inscriptions dynamic.

What has now been added to these inevitable consequences is the wrong, or nearly missed, reaction of institutional organisations, responsible for dealing with the post-emergency situation, unable to grasp the importance of the factor of residences for the students of the whole university system and the essentiality of its resolution in the short term.

This general consideration is the essential reason for this hypothesis, which is an answer to the significant reorganization of the university system of the regional capital of Abruzzo. However, this answer is connoted by an important symbolic meaning: considering the location of the building complex of San Salvatore in the historic center of the destroyed town, the rehabilitation project is shown as a flywheel able to trigger hoped virtuous processuality.

The establishment of new activities in the neglected site of the old core of the hospital can take the urban role of generator of redevelopment, establishing new relationships with the context, from urban and territorial scale to the individual building one, and a different relationship with the town, just by virtue of the features of public space and regenerator place that it would be destined to take.

The process of recovery of the historical buildings, in order to be effective and long-lasting, must first deal with the changing needs of its users, in view of the economic sustainability of the intervention. In fact, "the comparison with the economic feasibility is actually a decisional step as always essential, that becomes not only the main pass of the decisions and the intervention programs, but also the measure of the adequacy and technological efficiency of the possible solutions" [8].

The project proposal is part of a broader intervention that is the result of the approval, in 2003, of an Urban Renewal Programme in PRG variation, by the municipality of L'Aquila. It provided for the recovery of a net usable area equal to 14,730 square meters, replacement interventions over 5,700 square meters, extensions over 7,750 square meters, and works of primary and secondary urbanization and urban design.

With this zoning tool the municipality decreed the change of the intended use of the buildings included in it, from healthcare to directional, university and cultural use, sign of the will to redevelop an important area for the town, both from a logistical and functional point of view.

According to a first study there were identified intervention hypothesis on the total 18,200 square meters area to be recovered, of which approximately 7,000 square meters were for residential use and related services, 2,500 square meters for the university library, 4,800 for a center of advanced training and 1,500 for parking use.

In view of a unified project of this area, facing the issue of the refunctionalization of the complex in order to highlight its potentialities and allow the usability, the intervention has, therefore, provided for the insertion of new uses. All that in order to support the educational and teaching activities, whose demand is fully satisfied by the spaces allocated in the nearby headquarters of the Department of Human Sciences. 
On the basis of the study carried out on the development of the Italian and foreign campus [9], there were included university residences, recreational facilities, centers of higher education and linguistic centers, cultural services (libraries, exhibition centers and aggregation spaces), sports equipment, in order to allow the regeneration and the development even of the urban centers in which the intervention is set, fig. 3 .

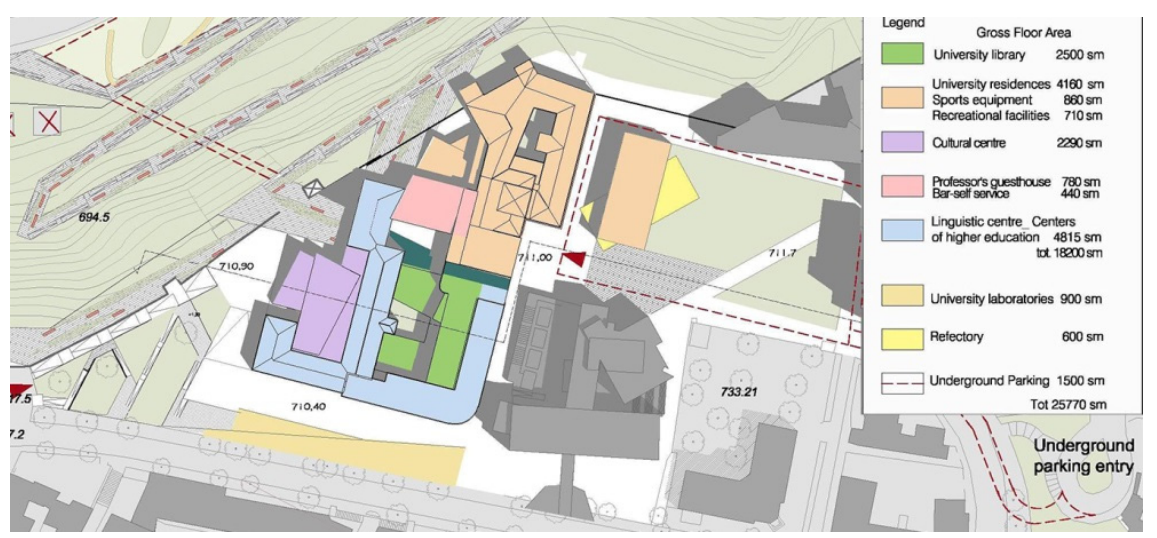

Figure 3: The design proposal of refunctionalization.

In order to preserve the existing without completely altering the spatial features, reorganizing the distribution system at the same time, there is the choice to adapt the spaces of the former hospital to functions that do not require large spaces, such as residences and a center of higher education. Instead, for functions that require larger spaces new extensions of the building complex were planned. As the area of intervention is located on the edge of the old town, it allows a connection between the historical town and suburbs to be established. This connection was created by a pedestrian path in the green adjacent to the walls, also providing its possible integration with a mechanized lift.

Considering the individual building, the issues of the integration, the existing and the reuse have been developed both through a volumetric-spatial additive process, with the extension of the building by adding new volumes, and superficial additive process, with the treatment of the building envelope [10].

From the figurative point of view, the main choice has been to preserve the typological courtyard of the complex creating urban squares to be used by the citizens and by university users, in order to create inclusive aggregation points.

\subsection{From the knowledge to the intervention strategies}

The processing of the project proposal has been carried out through a complex process of knowledge of the existing building, consisting of the historical, architectural and constructive analysis, in addition to structural damage and bioclimatic analysis [11]. In this way it was possible to highlight the obsolescence and therefore the loss of usability of the historical complex. 
From the static viewpoint, the structure presents a mild-moderate damage for the more recently built parts of the building and significant or severe damage for the part that includes the oldest section of the building complex and the expansion of the 1950s. It is evident the activation of some events of damage, caused by the many past interventions as well as the earthquake, such as cutting mechanisms, partial tilting or bending failure of the walls, irregularities between adjacent structures, with total collapses of the parts added to the original building.

Starting by highlighting the obsolescence, therefore the loss of value of the building, the current lack of physical, technical, distributive and safety requirements, the project included the demolition of all the additions and project discrepancies stratified, in order to regain the more consistent form with the history of the building. These elements, in fact, were not only worthless, but also subject to considerable damage, as well as responsible elements for a worsening of sunshine and ventilation condition of the courtyard of the building complex, occluded by them.

We have also opted for the rehabilitation and the static consolidation of the existing parts of the building complex, recovering all historic traces, that were figuratively and architecturally significant, using innovative materials and technologies as well as for the extension of the building through new elements that respect the original system. In order to maintain the typological system, in fact, the new volumes were in part underground, through spaces in the volume which allow the ventilation and the entrance of natural light, fig. 4.

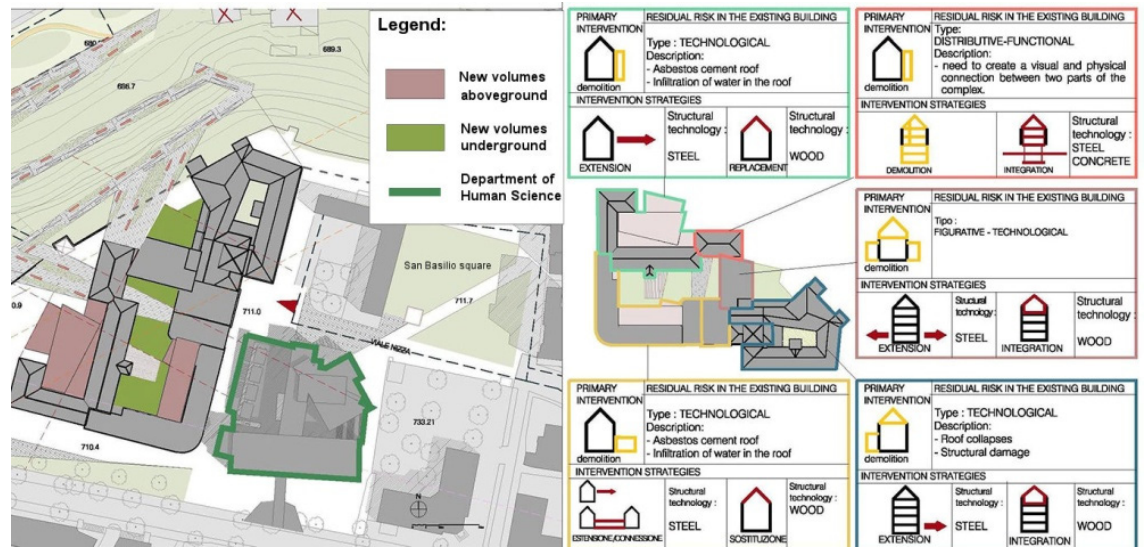

Figure 4: The new volumes and the strategies of intervention.

The technological solutions involved both the construction materials and the execution methods and choosing respectively wood (for the structural components of all the additions) and steel (prevalent structural component for new buildings) as construction materials and the dry process as prevalent constructive method [12].

From the architectural point of view the latter has been juxtaposed to the preexistence, without altering the typological features. The intervention mainly 
consists in the creation of three new blocks, suitably designed in the position, shape and size, in order to serve as finishing elements, physical and functional of the existing structures. The intervention is also aimed at the integration of a new volume in the existing building for the parts of the complex in which the emptying of the first floor is planned, leaving only the outer walls in respect of the original shape, fig. 5 .

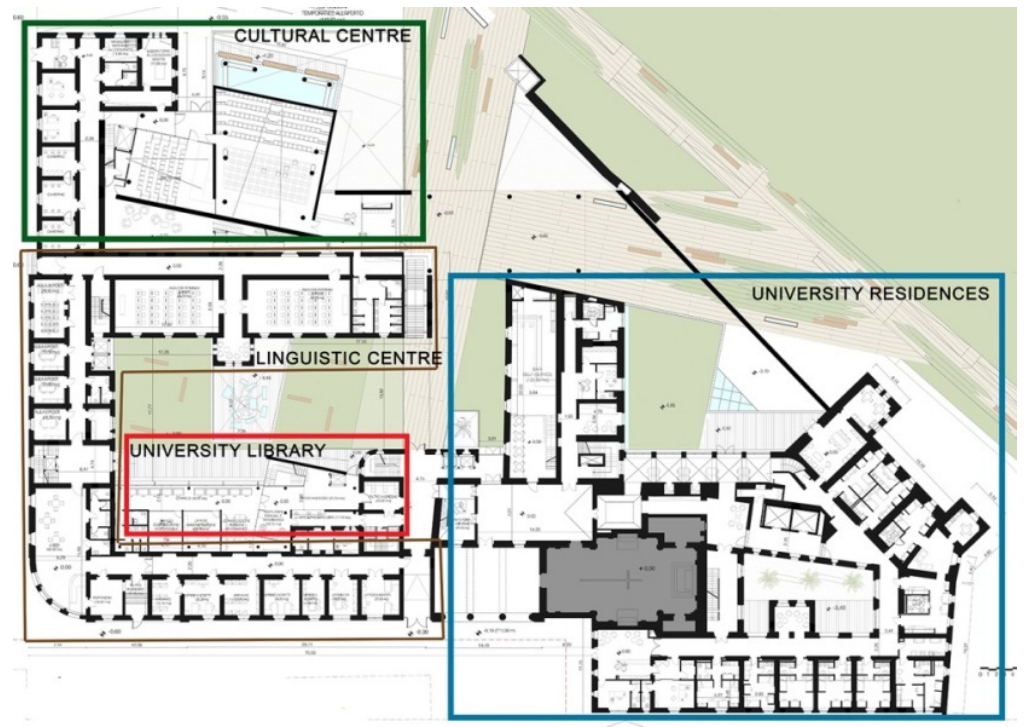

Figure 5: Floor plan of the project.

The new block, intended to be the cultural center, hosts public functions concerning the library and it is in direct contact, visually and physically, with the peripheral town. Inside it there is a public reading room, a newspaper library and a multifunctional hall that, through the use of folding seats, can, if necessary, be transformed into a conference room, meeting room for cultural events, or temporary exhibition hall. In this case the old building and the new are interdependent. The new volume compensates for the lack of vertical connective and of large spaces, which are necessary for the insertion of the intended use, previously described, approaching to the old, in which all support and service spaces are provided. The approach is filtered through the insertion of distribution spaces between the two buildings, whose roof is glazed, as a way to accentuate the recognizability of the intervention of expansion.

The block intended for the university library, is almost completely independent from the pre-existence instead. It consists of an underground part whose green roof becomes an open space usable by users, and a part above ground, characterized by glass surfaces properly diaphragmed using solar shading and microperforated cladding. The main study room of the library, on the basement floor is illuminated by a space created internally, which contains elements of reflection and control of the natural light, fig. 6 . 


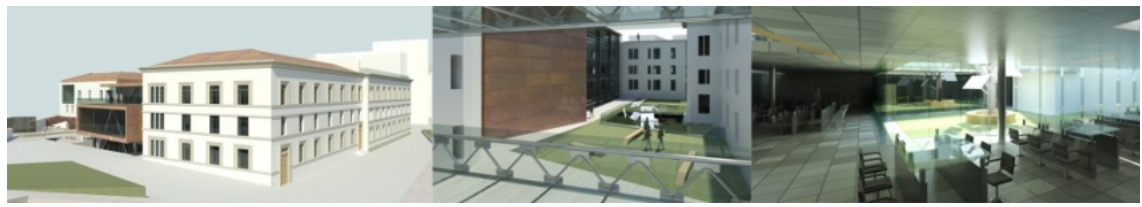

Figure 6: Photorealistic view of the block intended for the cultural centre and university library.

The oldest part of the building and the addition in the 1950s were finally used as university residences, guest quarters and related services, as well as a selfservice bar and a student's club (with study room, games and meetings), accessible from the outside and also usable from citizenship.

From a technological point of view, the integration of a new structure on the first floor was planned, as a result of the maintenance of the only perimeter walls. Having this plan an average height of about six meters, it was possible to build a loft for almost all mini apartments, furnished with a work plan/dining room and wardrobes. The rooms, mainly double, are designed in order to keep the privacy among students. Each room, accessible by a double-height horizontal connective, is characterized by a system of two entrances, separated by the stovetops, and two studio/bed spaces, divided by the staircase leading to the loft, fig. 7. Another type of intervention was necessary for the volume of the connection between the oldest part of the complex and the first extension of the 1930s. In order to create a double system of paths that connect the urban area of relevance with the lift outside the historic town, this volume was sectioned by removing the first two levels. However, on the upper floors the shape of the pre-existing was kept as an element of urban memory, becoming a sort of material shell of the new interior building. It appears, therefore, lifted from the ground and it creates a covered square for public pedestrian transit.

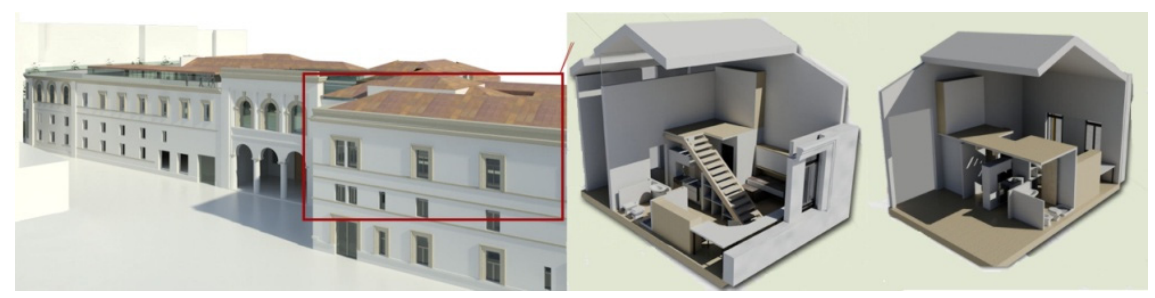

Figure 7: Internal and external photorealistic views of the new block intended for university residences.

Figurative aspects of all previous interventions have been translated into the choice of a single material for the coating, the Cor-Ten steel, with which all the elements of newly constructed buildings were treated, both new volumes and the integrations within the pre-existing, fig. 8. 


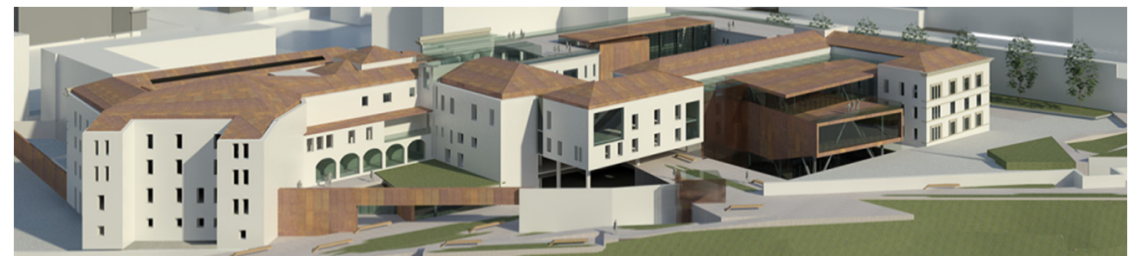

Figure 8: Photorealistic view of the whole project.

\subsection{Technological applications and energy efficiency}

For the symbolic value of the site it was deemed necessary to propose a rehabilitation project to be implemented with both innovative constructive techniques and with technologies oriented towards the maximum energy savings and the use of renewable energy sources.

Technology research has affected the portion of the building complex used for university residences, developing a technological analysis that faced the topics of seismic strengthening and improvement of energy performance. In the first case, being a traditional stone masonry construction with courses of brick, characterized by the presence of concrete curbs and stiff floors able to provide the "box behavior", the interventions consist in an operation on the foundations, with the expansion of the base of the building. They also consist in the projects aimed to increase the resistance of masonry elements, such as the indenting ("cuci-scuci" method) for injuries, the injections of grout to repair the injuries and the active containment of masonry with CAM system [13], fig. 9.
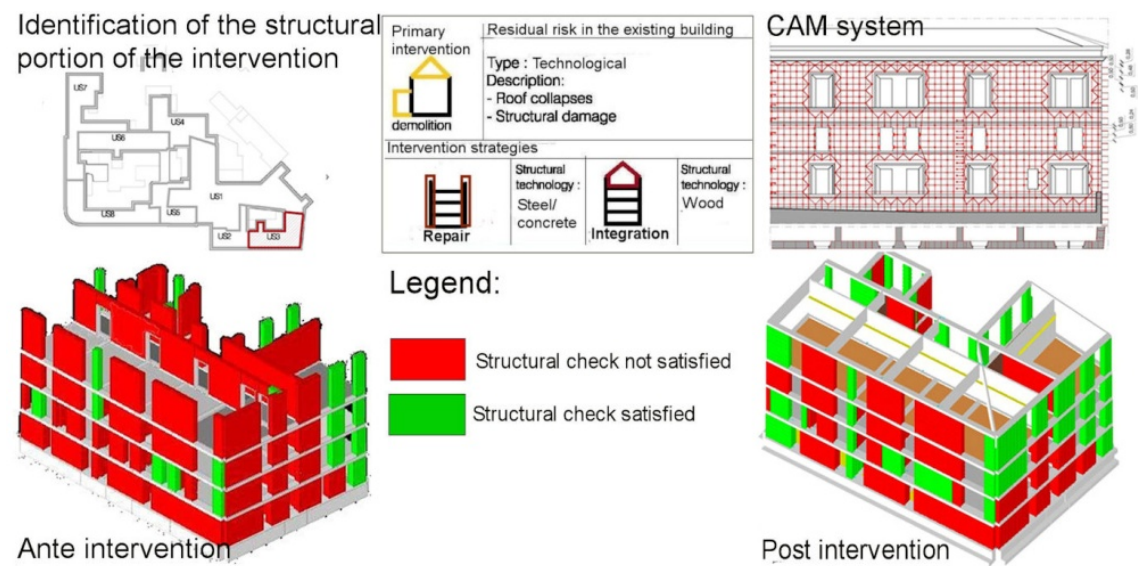

Figure 9: Structural analysis ante- and post-intervention, CAM System.

In addition, to improve the seismic performance, seismic joints between adjacent buildings with different origin were designed and the closing of unaligned compartments in the perimeter walls has been provided. From the structural point 
of view, the intervention of demolition of the top floor, except for the perimetral walls, allowed a new wooden structure to be inserted adjacent to the preexisting walls. Because of the total lack of transversal connections (windbracing walls) between the main walls, new elements were included in order to ensure a structural collaboration with the masonry, without increasing the loads on the pre-existence.

The system chosen is formed by self-supporting panels in X-LAM wood, characterized by high mechanical strength and, at the same time, by lightness. These panels, used both as floor and wall panels, properly fixed to the underlying masonry through the implementation of a new steel curb, share the load of the whole floor directly on the perimeter masonry piers, without compromising the overall functioning of the structure, fig. 10.

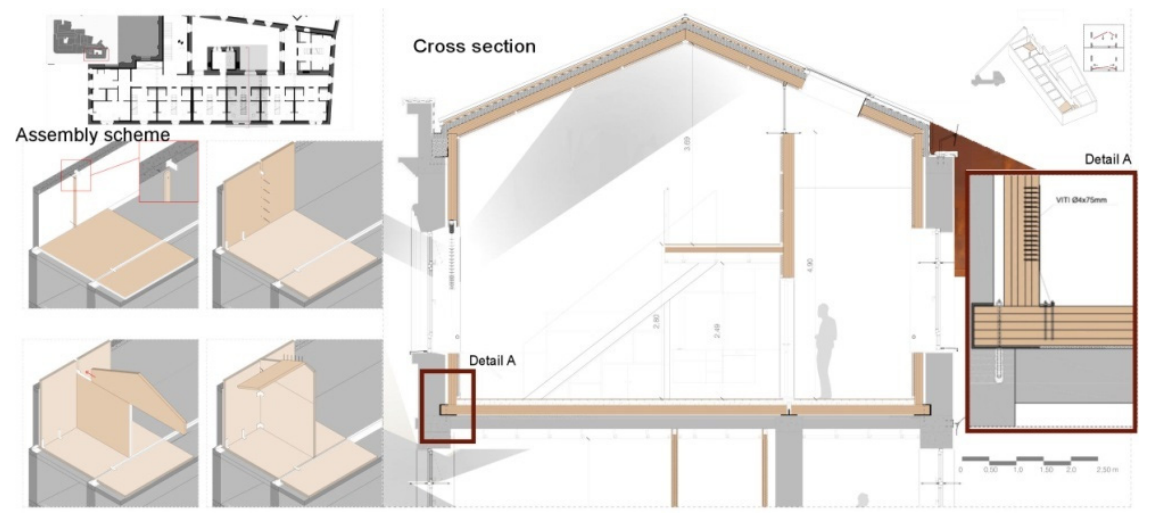

Figure 10: The new wooden structure adjacent to the pre-existing building.

All the previous interventions have improved the values of the indicators of seismic risk for each of the masonry walls significantly, increasing the security of the entire structure. Regarding the building envelope, after studying thermal and hygrometric features of all the vertical closings in the current state, composed exclusively of calcareous stone masonry, and of the horizontal closings, consisting of floor slabs in concrete and bricks, an improving intervention has been necessary, in order to adapt the latter to current legislation regarding the rehabilitation of buildings.

It was, therefore, planned to use thermal-break fixtures and a cladding system with internal and external insulation. For this purpose three types of insulation were used: for the outer thermal insulation, insulating panels and plasters based on aerogels of reduced thickness; granular foam-glass insulating panels for the insulation of the cover; panels of wood fibers pressed for the isolation from the inside [14].

The horizontal and vertical closures thermal verification was carried out both in steady state, with the assistance of the software Termus, and in dynamic state, using the software Design Builder. Using the latter, the illuminance interior levels of the spaces were also studied, finding a non-homogeneous distribution of 
daylight, which necessitated the installation of lightshelves and heliostats. In this way, with the steady-state analysis performed on the single horizontal and vertical closures after the intervention, both the limit values of transmittance and the limit values of condensation are verified. The dynamic state analysis has shown, however, an approximate $59 \%$ reduction of the winter heating requirement and a reduction in the value of internal relative humidity. As a result, however, there was a greater need for summer cooling: the building was well equipped with a heating/cooling floor system and with a controlled mechanical ventilation system (VMC), also to avoid any condensation caused by the cooling floor system.

Finally, respecting the historic character of the building, an integrated photovoltaic system has been installed on the new roof that, on the basis of analysis, generates an energy production equal to approximately $40 \%$ of the total requirement.

The technological devices planned, such as the use of heating/cooling systems and controlled mechanical ventilation, the integration of control elements of natural light, the use of renewable resources, have allowed the energy efficiency of the building and the comfort levels of the interior spaces to improve.

\section{Conclusions}

The case study illustrated shows how, in the urban area of our towns, meant as the field on which the complex system of relationships acts, consisting of building structures, infrastructures and human activities, the reuse of existing buildings can be a fundamental occasion of requalification of the built environment. The dynamic and uncertain contemporary landscape, appears, then, as an element of the project that determines the process of refunctionalization through the creation of a new space for functions and use. It is able to reconnect margins and infrastructures, in order to find new relationships between the historic town and the new urban dimension. The settlement of a new university in the disused site of the old hospital of San Salvatore, directed to take the role of urban function generator of rehabilitation, aims to solve the correlation with the context, rereading the relationship with the town just in virtue of the characteristics of public space and place regenerator.

In this direction, the application of a compatible design strategy, allows the application of innovative technological solutions, able to increase the performance indices of the building, while respecting the historical pre-existence and its values.

\section{Acknowledgements}

The project was developed in the degree thesis of Eng. Luisa Capannolo, "Strategic Plan for the development of University of Study of L'Aquila: Sustainable and energy-efficient rehabilitation of the former hospital of San Salvatore in L'Aquila", supervisor Prof. Eng. Pierluigi De Berardinis, a.a. 20132014.

All the images were elaborated in the degree thesis of Eng. Luisa Capannolo, "Strategic Plan for the development of University of Study of L'Aquila: 
Sustainable and energy-efficient rehabilitation of the former hospital of San Salvatore in L'Aquila", supervisor Prof. Eng. Pierluigi De Berardinis, a.a. 20132014.

\section{References}

[1] Malighetti, L. E., Recupero edilizio. Strategie per il riuso e tecnologie costruttive, Il Sole 24 Ore, Milano, 2011.

[2] Turchini, G., Garanzie di successo negli interventi di recupero, in Arketipo n. 20, pp. 46-47, 2008.

[3] Stockel, G., La Città dell'Aquila, Edizione Gallo Cedrone, L'Aquila, 1981.

[4] Tozzi, A., L'Ospedale San Salvatore dell'Aquila nel passato e nel presente, Tip. F.lli Centofanti, L’Aquila, 1956.

[5] Guarino, M., Vittorini, M., Studi preparatori per la realizzazione di un centro ospedaliero a L'Aquila, L'Aquila, 1968.

[6] Centofanti, M., L'Aquila 1753-1983: il restauro della città, Ed. Libreria Colacchi, L'Aquila, 1984.

[7] Centofanti, M., Brusaporci, S., Il disegno della città e le sue trasformazioni, in Città e Storia, n.1, a. VI, 2011.

[8] Zambelli, E. (a cura di), Ristrutturazione e trasformazione del costruito. Tecnologie per la rifunzionalizzazione e trasformazione del costruito, Il Sole 24 Ore S.p.A., Milano, 2004.

[9] AA. VV., Università di Roma, Fac. Ingegneria (a cura di), Edilizia universitaria. Spazi funzionali e standards dimensionali, DEI, Roma, 1981.

[10] Imperadori, M. (a cura di), Costruire sul costruito, Carocci Editore, Roma, 2001.

[11] Sala, M., Recupero edilizio e bioclimatica: strumenti, tecniche e casi di studio, Esselibri, Napoli, 2001.

[12] De Berardinis, P., Costruire sostenibile, in L'industria delle Costruzioni, n. 393, 2007.

[13] Tubi, N., Silva, M. P., Ditri, F., Gli Edifici in Pietra. Recupero e costruzione - Murature, solai, Analisi bioclimatica e ambientale, Sistemi Editoriali, Napoli, 2009.

[14] Jelle B. P., Traditional, state-of-the-art and future thermal building insulation materials and solutions - Properties, requirements and possibilities, in Energy and Buildings n. 43, 2011. 